\title{
Diesel emissions from Euro II/III buses of Bogota's urban transport system: the challenge is not reducing mass, but counting particles
}

\author{
M. C. Cortes ${ }^{1}$, H. R. Acevedo ${ }^{2} \&$ N. Y. Rojas ${ }^{3}$ \\ ${ }^{1}$ Department of Chemical and Environmental Engineering, \\ National University of Colombia, Colombia \\ ${ }^{2}$ Department of Mechanical and Mechatronics Engineering, \\ National University of Colombia, Colombia \\ ${ }^{3}$ Department of Chemical and Environmental Engineering, \\ National University of Colombia, Colombia
}

\begin{abstract}
Bogota's public transportation system has had dramatic changes in the last decade, but its fleet of 12,000 diesel buses is still one the main sources of fine particulate matter, affecting the health of its nearly 8 million inhabitants. Perhaps the most significant factor that explains the toxicity of particulate matter is particle number, rather than particulate mass. Therefore, developing strategies to reduce diesel engine particulate number emissions, and not only their mass, is one of the main purposes of Bogota's environmental agency. Currently nanoparticle studies developed by Bogota's environmental agency shows that the interval of $1.72 \times 10^{5}$ $-2.22 \times 10^{5} \mathrm{p} \mathrm{cm}^{-3}$ is the concentration in particle number inside the public transportation system's buses one of the main ways of the city.

This work aimed to measure particle number emissions from Euro II and Euro III buses under different load conditions on a chassis dynamometer. The buses operate with diesel B2/B4 fuel with $50 \mathrm{mg} / \mathrm{kg}$ of sulfur (ASTM D-2622) and $0.01 \mathrm{~g} / 100 \mathrm{~g}$ (ASTM D482) of ash. Two 50-passenger and four 160-passenger buses, the Euro II and Euro III, were tested. Particle counting and particle size distribution were determined using a NanoMet 3 diffusion counter.

Mass size distributions showed the same trend as number size distribution, but shifted in a proportion equal to the mass median diameter over median diameter
\end{abstract}


count. Regardless of the engine's emission standard, most of the particle sizes were in the nucleation mode.

Keywords: aerosol, diesel emission, engine, particle matter, particulate count, nanoparticles.

\section{Introduction}

Aerosols have a significant effect on public health and climate have given rise to the study of the size distribution of the nanoparticles from internal combustion engines. According to Theodoreos et al. [1] passenger diesel technology Euro IV vehicle equipped with after-treatment devices (DPF - Diesel Particle Filter) can form nucleation mode particles at high speed despite using fuel with sulfur levels below $10 \mathrm{ppm}$. The World Bank indicated that diesel particle smaller than 1 micron in diameter have a potential carcinogen due large surface area that adsorbs polycyclic and nitro-polycyclic hydrocarbons [2].

Several authors agree that mass-based particulate emission standards are not appropriate in order to monitoring ultrafine particles. During sampling processes, particulate mass tends to be conserved while particle number is not, because nuclei and coagulation reactions [3]. Thus, the mass, number, volume or surface size distribution functions must be considered.

In view of the current evolution of the emission standards, big cities aim to characterize emissions from their urban transport systems. Bogota, a city with about 12,300 Euro II/ Euro III/ Euro IV diesel vehicles, is establishing policies to reduce emissions of ultrafine particles $[5,6]$. As part of this process, a campaign was designed to determine particle number and particle size distribution in emissions from diesel buses through chassis dynamometer on-road tests.

This paper presents the results of the chassis dynamometer tests (MD-250 Chassis Dynamometer System; 25\%, 50\% and 75\% load) conducted on two 50passenger Euro-III and two 160-passenger Euro II buses, to determine ultrafine particle number and number size distribution, using a NanoMet3 diffusion counter.

\section{Measurements}

\subsection{Instruments}

The Nanomet3 is a diffusion particle counter that works in the range of 10 to $300 \mathrm{~nm}$. Measurement equipment features a separate exhaust probe and control unit that dilutes the sample at the source in order to preserve it. NanoMet3 is completed with a Diffusion Size Classifier (DiSC), an instrument to measure number concentration and average diameter of nanometer sized particles [4].

\subsection{Chassis dynamometer tests}

An MD-250 Mustang Chassis dynamometer ${ }^{\circledR}$ was used. The MD-250 simulated $25 \%, 50 \%$ and $75 \%$ loads. The MD- 250 consists of a drive roll set (40" face length), an idler roll set, a power absorbing unit (PAU), a load cell, and a speed encoder. During its operation, the vehicle's drive wheels are cradled between the 
drive rolls and the idler rolls. The "load" is measured by the load cell and transmitted to the control system via an electric signal. In each test, the horsepower is determined.

Each load test was performed for about 5 min and repeated 3 times. Euro III buses tests presented instability at $75 \%$ loads. This instability was attributed to the inability of the brake where it is unable to maintain the values of high power for a long time.

(a)

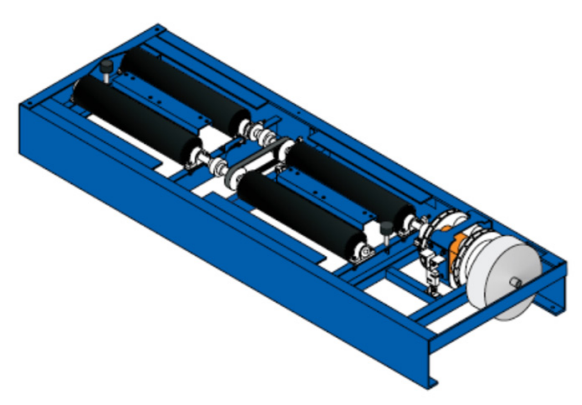

(b)

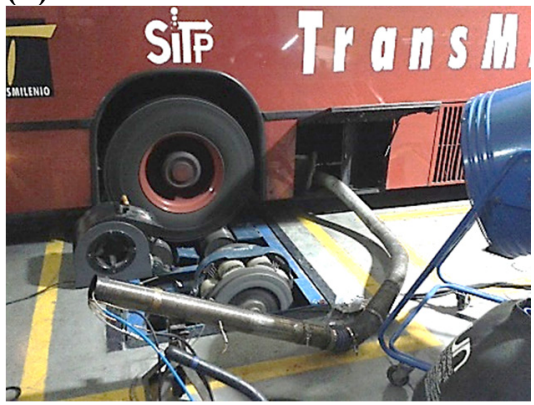

Figure 1: MD-250 Mustang chassis dynamometer system: (a) outline and (b) site measurement.

\subsection{Tested buses}

Six buses were tested on chassis dynamometer as is described in Table 1. The tested buses have the most used in the city with a $61.3 \%$ of Volvo engines in Euro II, and a $49.1 \%$ of Scania in Euro III [6]. The tests were performed in agreement with the buses owners and the local government.

In two Euro III buses with different capacity and driver cycle (EIII-160-01DPF and EIII-50-01-DPF) was installed an emission controller device or retrofit known as Diesel Particle Filter (DPF).

Table 1: $\quad$ Tested buses features.

\begin{tabular}{|c|c|c|c|c|c|c|c|}
\hline ID & $\begin{array}{l}\text { Emission } \\
\text { Standard }\end{array}$ & 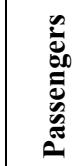 & Brand & Reference & $\underset{\nu}{\bar{\nu}}$ & $\begin{array}{c}\text { Displace- } \\
\text { ment } \\
\left(\mathrm{cm}^{3}\right)\end{array}$ & $\begin{array}{c}\text { Maximum } \\
\text { Capacity } \\
(\mathrm{kW})\end{array}$ \\
\hline EII-160-01 & \multirow{3}{*}{ Euro II } & \multirow{2}{*}{160} & $\begin{array}{l}\text { Mercedes } \\
\text { Benz } \\
\end{array}$ & O400 UPA & 2005 & 9973 & 168 \\
\hline EII-160-02 & & & \begin{tabular}{|l|} 
Mercedes \\
Benz
\end{tabular} & OM449LA & 2001 & 9973 & 136 \\
\hline EII-50-01 & & 50 & Agrale & MA8,5 TCA & 2004 & 4300 & 107 \\
\hline EIII-160-01 & \multirow{3}{*}{ Euro III } & \multirow{2}{*}{160} & Scania & K310 & 2007 & 9000 & 170 \\
\hline EIII-160-02 & & & Volvo & B12M & 2007 & 12100 & 183 \\
\hline EIII-50-01 & & 50 & $\begin{array}{l}\text { Mercedes } \\
\text { Benz }\end{array}$ & LO915 & 2010 & 4249 & 108 \\
\hline
\end{tabular}




\section{Results and discussions}

\subsection{Influences of vehicles load on nanoparticles size distribution}

To analyze the influence of vehicle load in the nanoparticle size distribution a 0 , 25,50 and $75 \%$ load imposition in the MD-250 and the location of a measurement equipment (NM3) on exhaust buses were needed. The $0-75 \%$ load range is important since low load levels allows to identify the particle number concentration under high accelerations and fluctuating speed changes.

The data validation was based on the application of descriptive statistics in each of the performed tests by load and bus. Each Euro II buses were tested three times for every load ( $0-75 \%$ ), while the Euro III buses had the same pattern for 0 to $50 \%$ of load. Once the data was compiled, the lowest typical error result was selected. None of the typical error was higher than 2.0 (shown in Table 2).

Table 2: Descriptive statistics Euro II buses.

\begin{tabular}{|l|c|c|c|c|c|c|c|c|c|c|c|c|}
\hline \multicolumn{1}{|c|}{ Bus } & \multicolumn{4}{|c|}{ EII-160-01 } & \multicolumn{4}{c|}{ EII-160-02 } & \multicolumn{3}{c|}{ EII-50-01 } \\
\hline \multicolumn{1}{|c|}{ Load (\%) } & $\mathbf{0}$ & $\mathbf{2 5}$ & $\mathbf{5 0}$ & $\mathbf{7 5}$ & $\mathbf{0}$ & $\mathbf{2 5}$ & $\mathbf{5 0}$ & $\mathbf{7 5}$ & $\mathbf{0}$ & $\mathbf{2 5}$ & $\mathbf{5 0}$ & $\mathbf{7 5}$ \\
\hline Average & 36.5 & 38.4 & 45.7 & 44.6 & 63.1 & 68.5 & 71.4 & 82.1 & 41.0 & 35.9 & 35.8 & 34.9 \\
\hline $\begin{array}{l}\text { Typical } \\
\text { Error }\end{array}$ & 0.1 & 0.1 & 0.3 & 0.5 & 0.3 & 0.4 & 1.8 & 0.7 & 1.1 & 0.2 & 0.2 & 0.1 \\
\hline Median & 36 & 38 & 45 & 43 & 63 & 68 & 68 & 80 & 40 & 36 & 36 & 35 \\
\hline Mode & 36 & 39 & 45 & 40 & 62 & 63 & 66 & 75 & 29 & 36 & 35 & 34 \\
\hline $\begin{array}{l}\text { Standard } \\
\text { Deviation }\end{array}$ & 1.2 & 1.4 & 4.3 & 6.9 & 5.2 & 7.0 & 22.2 & 11.0 & 13.1 & 2.4 & 2.1 & 1.9 \\
\hline Variance & 1.4 & 2.1 & 18.8 & 47.1 & 27,2 & 49.0 & 493.8 & 120.7 & 172.4 & 5.6 & 4.6 & 3.7 \\
\hline Range & 5 & 6 & 24 & 42 & 41 & 52 & 249 & 57 & 62 & 14 & 10 & 18 \\
\hline Minimum & 34 & 36 & 37 & 31 & 48 & 53 & 51 & 61 & 22 & 32 & 31 & 31 \\
\hline Maximum & 39 & 42 & 61 & 73 & 89 & 105 & 300 & 118 & 84 & 46 & 41 & 49 \\
\hline Count & 92 & 175 & 223 & 161 & 383 & 252 & 160 & 275 & 146 & 131 & 145 & 199 \\
\hline $\begin{array}{l}\text { Confidence } \\
\text { Level } \\
\text { 95\%) }\end{array}$ & 0.24 & 0.22 & 0.57 & 1.07 & 0.52 & 0.87 & 3.47 & 1.30 & 2.15 & 0.41 & 0.35 & 0.27 \\
\hline
\end{tabular}

Figures 2(a) and 2(b) shows that from the Euro II buses tested with a $0 \%$ load, the EII-160-02 bus presented the largest amount of particles with sizes higher than $54 \mathrm{~nm}$ unlike the two remaining buses, which reported their higher frequency for 20 and $25 \mathrm{~nm}$ particles, despite of having $\sim 1-70 \times 10^{8} \mathrm{p} / \mathrm{cm}^{3}$.

The number of particles (NP) rises with the particle size reduction in every load. Each bus shows higher NP with particles sizes: 35-37 nm (EII-50-01), 63$72 \mathrm{~nm}$ (EII-160-02), and 35-45 nm (EIII-160-01). The 2001 model bus presented the higher sizes beside the remaining buses in the same standard emission. The 
Figure 3 shows that the EII-160-01 bus emits the higher amount of diesel particles reaching the $\sim 4.8 \times 108 \mathrm{p} / \mathrm{cm}^{3}$ concentrations.

(a)

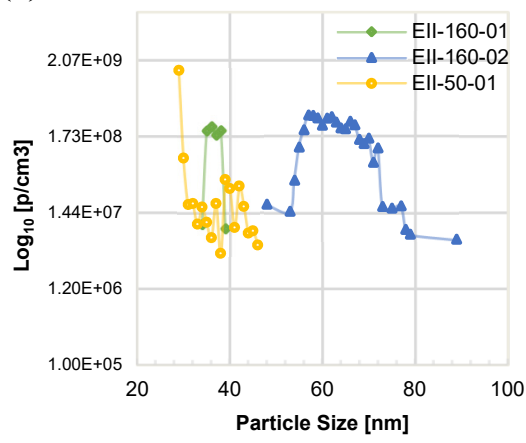

(b)

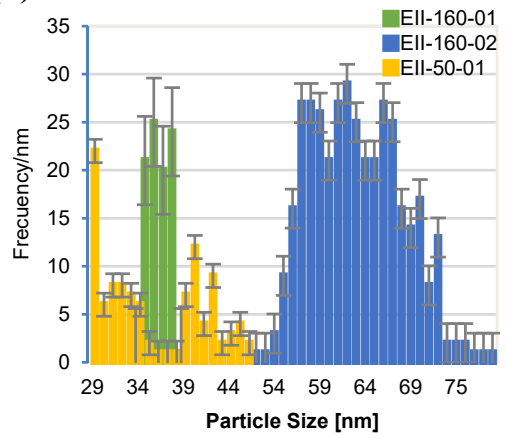

Figure 2: $\quad$ Size distribution with $0 \%$ load: (a) count and (b) frequency.

With a load of 50\% (Figure 4), the EII-160-01 and EII-50-01 buses behavior is similar in frequency and number of particles. From the third bus part, with particles sizes higher than $51 \mathrm{~nm}$, the NP concentration is lower. However, when the highpeople-capacity bus is exposed to the greatest amount of loads (Figure 5), particles under $37 \mathrm{~nm}$ govern the distribution with concentrations up to $2.1 \times 10^{9} \mathrm{p} / \mathrm{cm}^{3}$ in its highest peak.

(a)

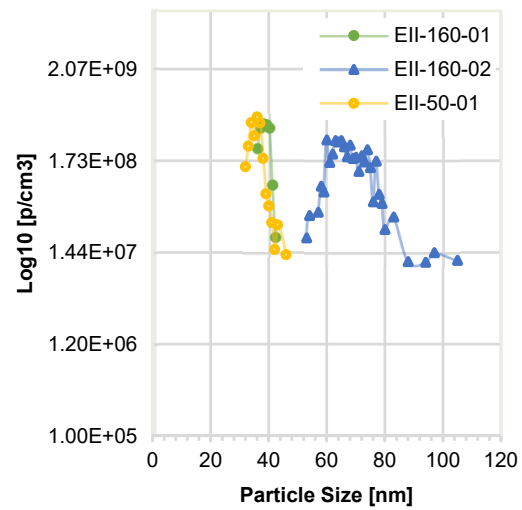

(b)

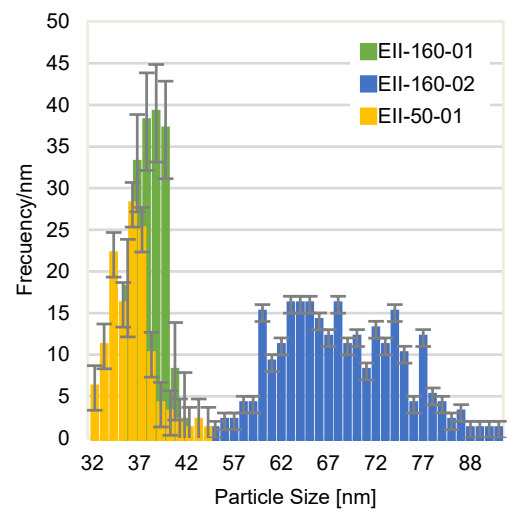

Figure 3: $\quad$ Size distribution with $25 \%$ load: (a) count and (b) frequency. 
(a)

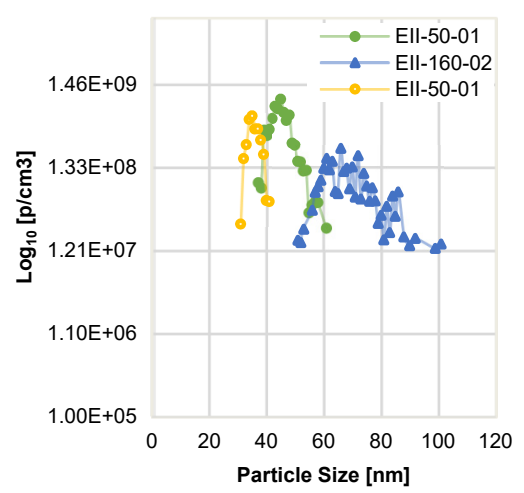

(b)

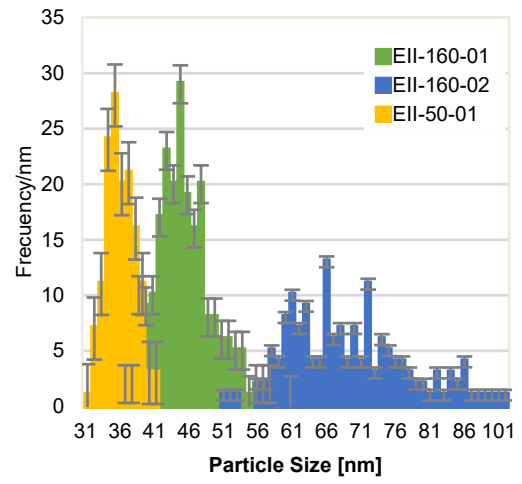

Figure 4: $\quad$ Size distribution with a 50\% load: (a) count and (b) frequency.

In all of the loads tested, the same measurement instruments were used at conventional temperature and humidity conditions. The number particle concentration (NP) presented its highest value with size $\sim 45 \mathrm{~nm}$ increasing order of magnitude in the highest load. The results indicate that the vehicles load affects the number of particles maintaining similar trends. However, the lowest displacement engine represented the highest amount of particles with the lower size and the major concentration in NP.

(a)

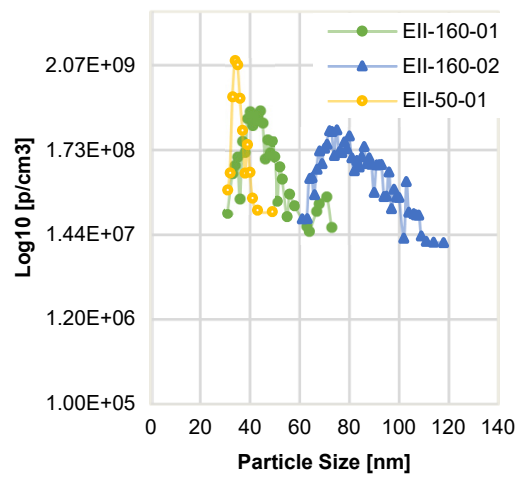

(b)

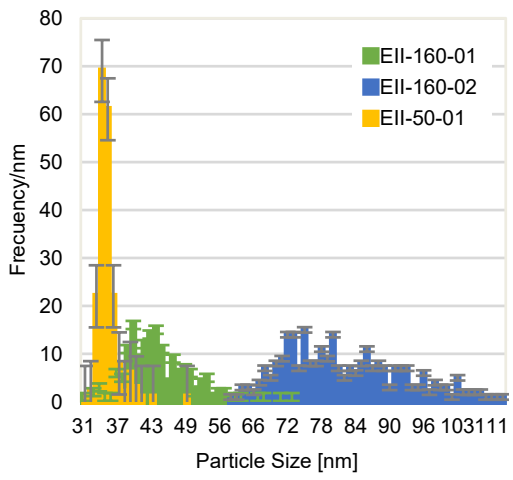

Figure 5: $\quad$ Size distribution with a 75\% load: (a) count and (b) frequency.

Regarding the Euro III buses (Table 3), 75\% load tests were not reported for presenting values with standard deviation higher or lower than expected. During the tests, the buses did not reach steady state conditions at $75 \%$ load, changing the vehicle speed variations and real-time emissions measurements. 


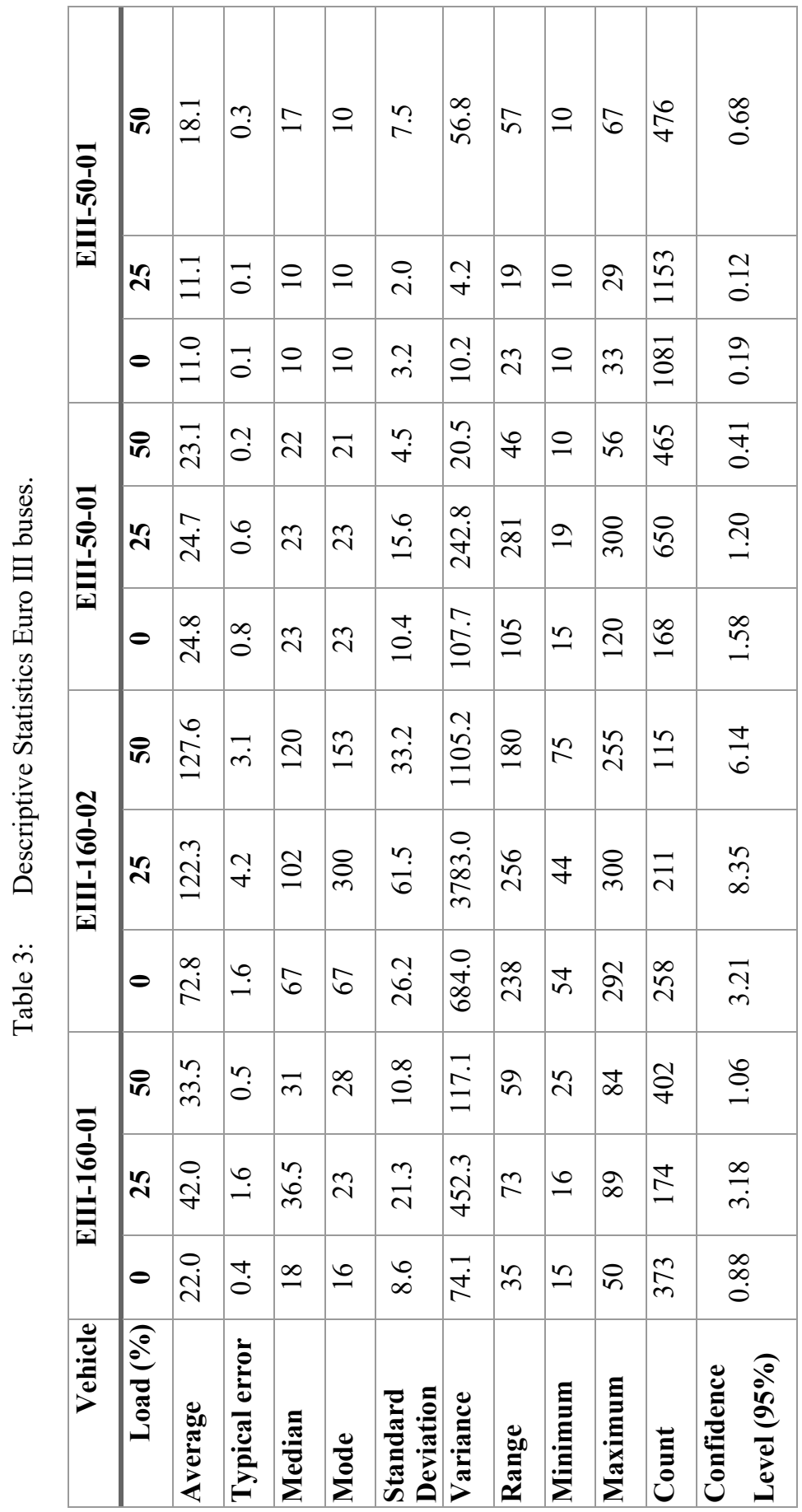


Figures 6 and 7 explain that the removal efficiency of DPF devices overcomes $90 \%$. Despite the $0 \%$ load conditions are the less restrictive compared to the other tested loads, the concentration average value not differs from the results at $25 \%$ and 50\%. In addition, the EIII-160-01 bus without after treatment (DPF) presented the lowest particles amount concentration.

(a)

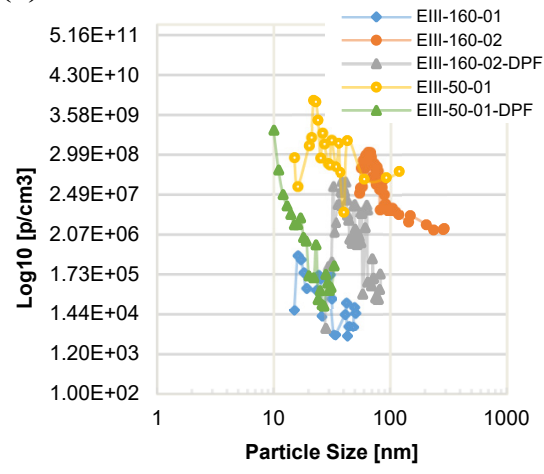

(b)

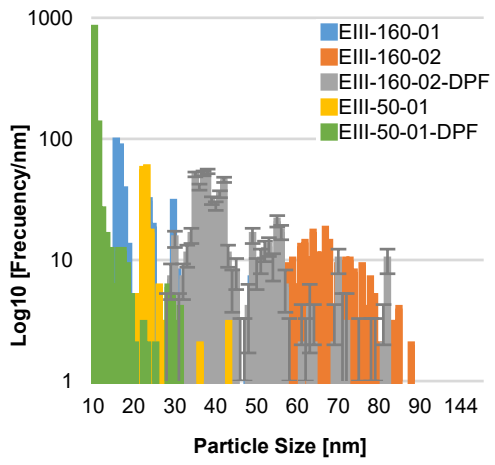

Figure 6: Size distribution with a $0 \%$ load: (a) count and (b) frequency.

(a)

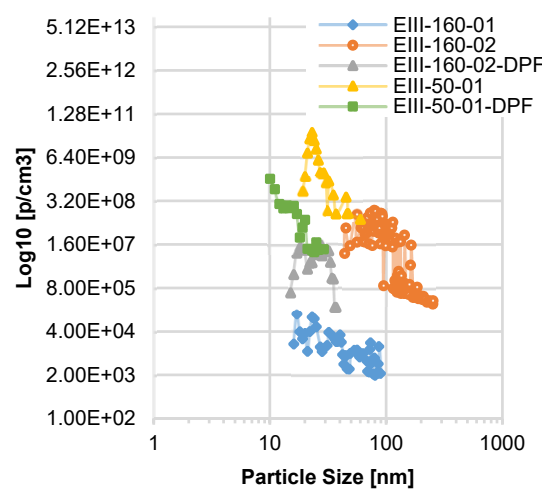

(b)

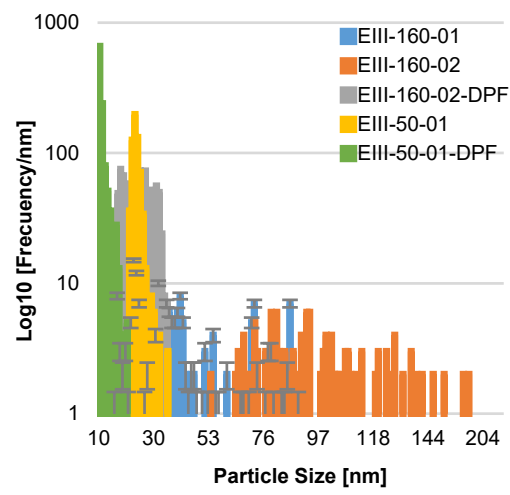

Figure 7: $\quad$ Size distribution with a 25\% load: (a) count and (b) frequency.

The size frequency distributions do not change by load or capacity effects. The larger quantity of small particles is emitted by 50-passenger buses with or without DPF, as the only engine bus identified as EIII-160-01. 
(a)

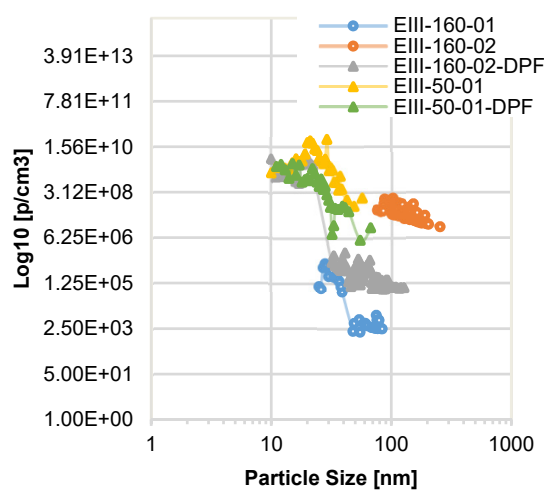

(b)

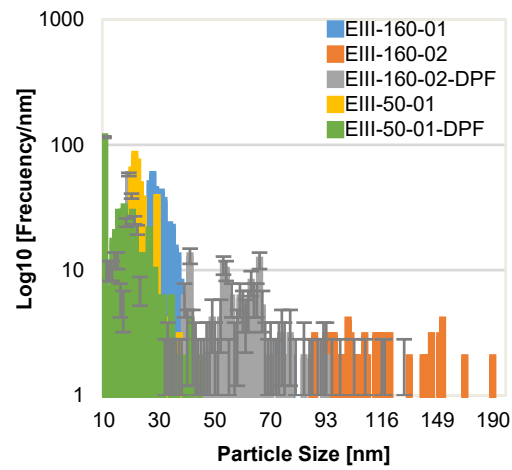

Figure 8: $\quad$ Size distribution with a 50\% load: (a) count and (b) frequency.

\subsection{Influence of retrofit (DPF) on number and mass particle buses}

In all the loads, EIII-50-01-DPF bus presented a raise in frequency and particle number concentration (NP) start of the test. This special condition is probably given because of the DPF with active function. Dwyer et al. [9], found in the DPF evaluated diesel-engine vehicles that the total time of a test regeneration is more than 10 minutes. In this case, at the beginning of the tests the electric heating system did not manage to maintain the regeneration temperatures needed, this is why $50 \%$ of the load (the relation between final concentration (Npe) and initial concentration (Npi)) was 0.0017 modifying its value in three orders of magnitude. Unlike the above, the passive operation principle EIII-160-02 bus, with a $50 \%$ higher load of small or ultra-fines particles $(\sim 45-80 \mathrm{~nm})$, emitted 0.11 keeping the $\mathrm{Np}_{\mathrm{f}} / \mathrm{Np}_{\mathrm{i}}$ relation.

(a)

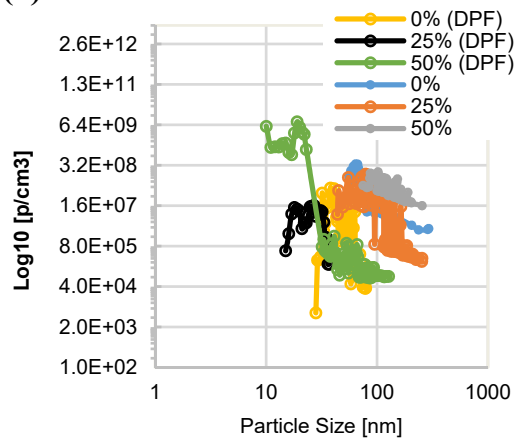

(b)

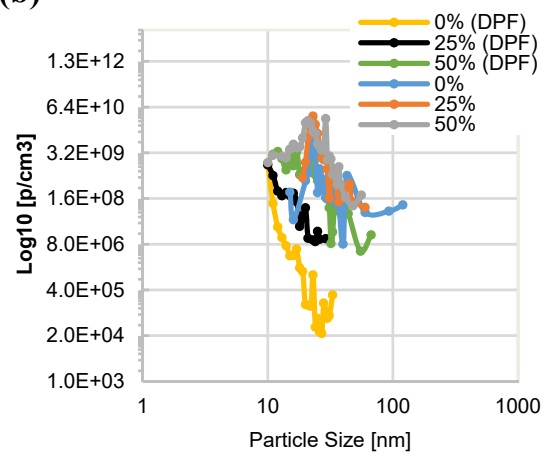

Figure 9: Count size distribution: (a) EIII-160-02 and (b) EIII-50-01. 


\subsection{Comparison between mass and number particle concentration}

As NanoMet3 measurement device measures directly the amount of particles concentration (NP) and not their mass (MP), the mass concentration (MP) was estimated considering an aerodynamical diameter particle with sphere shape and known density, [7]. The mass and number particles size distributions in the Euro III 160-passenger bus with and without DPF (Figure 10) and the 50-passenger bus (Figure 11) from the same emission standard show that the DPF filter does not remove the number of particles (NP) in the same portion than the mass particle (MP) removal, even they maintain efficiency values higher than 90\% [11]. Bergmann et al. [14] found higher removal efficiency in a DPF equipped Euro IV

(a)

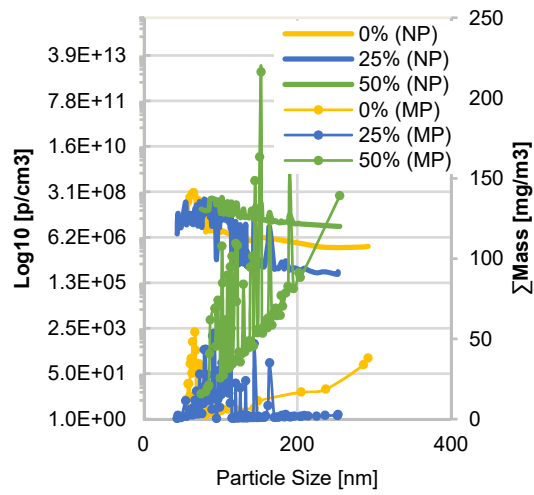

(b)

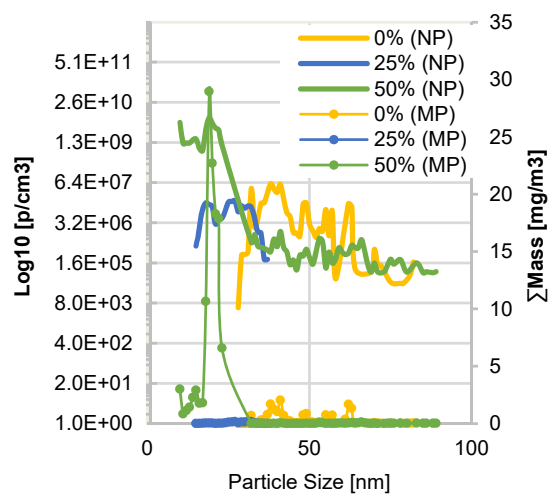

Figure 10: Size distribution: (a) EIII-160-02 and (b) EIII-160-02 DPF.

(a)

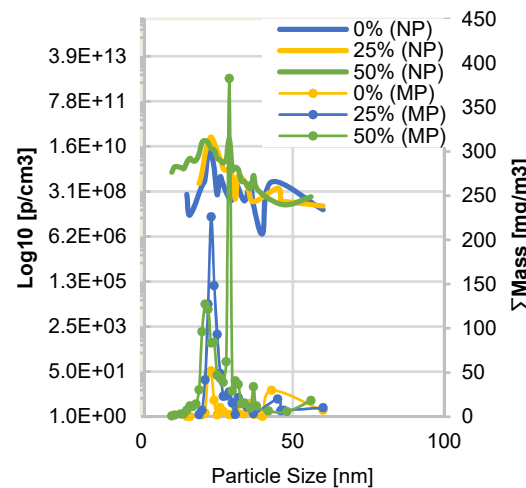

(b)

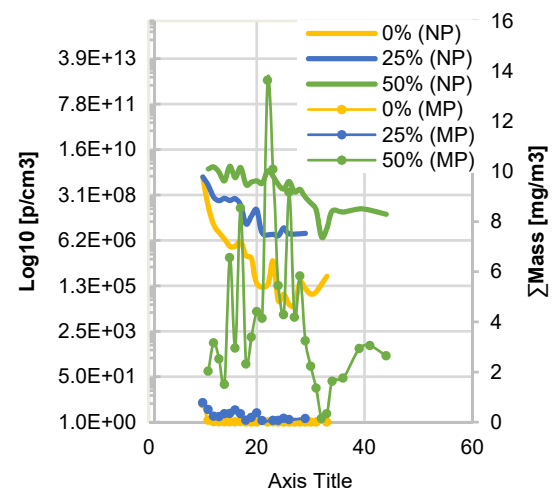

Figure 11: Size distribution: (a) EIII-50-01 and (b) EIII-50-01 DPF. 
diesel vehicle during New European Driving Cycle (NEDC) with 99.5\% respect to number NP and $99.3 \%$ for PM mass. In the Bogota tested buses conditions, the filtration efficiency of $50 \%$ load is $99.8 \%(\mathrm{NP})$ and $99.3 \%$ (MP).

The use of DPF filter in the 160-passenger bus allows the concentration in number of particles at $50 \%$ load was lower than the 50-passenger bus were it was the highest. The EIII-50-01-DPF 50\% load bus mass concentration (MP) presented a similar behavior with and without filter.

\section{Conclusions}

For the diesel bus studied on chassis dynamometer, (PM) and (NP) concentrations are in general correlated. The data validation was based on the application of criteria of the descriptive statistics in each of the performed tests by load and bus tested. However, due load instability during the operation on chassis, it is not possible to bring the Euro III buses at $75 \%$.

According the size distribution, the results with the least restrictive load $(0 \%)$ in all cases do not represent the lowest concentrations compared with 25, 50 and $75 \%$ loads. PM concentrations were more sensitives to the changes of loads. Although efficiencies always exceeded $90 \%$ in both concentrations PM and NP.

Although one of the Euro III buses tested did not have after treatment, this had the lowest concentration of the testes buses in average of $1.4 \times 10^{5}$ particles $/ \mathrm{cm} 3$ in $50 \%$ load with particles sizes of $\sim 35 \mathrm{~nm}$, nucleation range.

\section{References}

[1] T. Theodoreos, L. Leonidas and S. Zissis, "Diesel passenger car PM emissions: From Euro 1 to Euro 4 with particle filter," Atmospheric Environment, pp. pp. 909-916, 2010.

[2] World Bank, "South Asia Urban Air Quality Management Briefing Note No. 13," [Online]. Available: http://siteresources.worldbank.org/ PAKISTANEXTN/Resources/UrbanAir/ScienceOfHealthImpact.pdf. [Accessed 2016].

[3] J. B. Heywood, Internal Combustion Engine Fundamentals, United States of America: McGraw-Hill, Inc., 1988.

[4] L. Tiezhu, C. Xudong and Y. Zhenxing, "Comparison of fine particles emissions of light-duty gasoline vehicles from chassis dynamometer tests and on-road measurements," Atmospheric Environment, no. 68, pp. 82-91, 2013.

[5] Resolucion 00088, 2015.

[6] Resolucion 00123, 2014.

[7] Testo Company, "NanoMet3. User Manual," Matter Aerosol AG, Switzerland, 2012.

[8] Transmilenio SA, "Vehicle classification," Bogota DC, 2013.

[9] H. Dwyer, A. Ayala, S. Zhang, J. Collins, T. Huai, J. Herner and W. Chau, "Emissions from a diesel car during regeneration of an active diesel particulate filter," Journal of Aerosol Sciencie, no. 41, pp. 541-552, 2010. 
[10] W. C. Hinds, Aerosol Technology, Canada: John Wiley \& Sons, Inc., 1999.

[11] D. B. Sonntag, O. Gao and B. A. Holmén, "Comparison of particle mass and number emissions from a diesel transit bus across temporal and spatial scales," Transportation Research Part D, no. 25, pp. 146-154, 2013.

[12] Ecopetrol, "Technical Specifications Diesel B2/B4," Ecopetrol, 2016.

[13] Bogota's Environmental Agency, "Exposición Personal A Nano-Partículas en buses de Transmilenio en el corredor vial de la Avenida Caracas en la Ciudad de Bogotá," Bogota, 2016.

[14] M. Bergmann, U. Kirchner, R. Vogt and T. Benter, "On-road and laboratory investigation of low-level PM emissions of a modern diesel particulate filter equipped diesel passenger car," Atmospheric Environment, no. 43, pp. 1908-1916, 2009. 